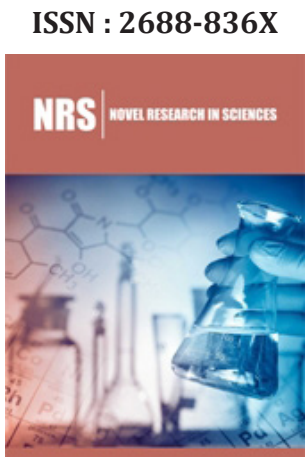

*Corresponding author: Haidar Fadhil AL Qrimli, Studies Planning and Follow Up Department, Midland Refineries Company, Ministry of Oil, Baghdad, Iraq

Submission: 眥 July 02, 2019

Published: 盇August 28, 2019

Volume 1 - Issue 5

How to cite this article: Haidar Fadhil AL Qrimli. Emerging Issues in Engineering Science and Implications for Employers and Newly Graduates. Nov Res Sci.1(5). NRS.000524.2019.

DOI: 10.31031/NRS.2019.1.000524

Copyright@ Haidar Fadhil AL Qrimli, This article is distributed under the terms of the Creative Commons Attribution 4.0 International License, which permits unrestricted use and redistribution provided that the original author and source are credited.

\section{Emerging Issues in Engineering Science and Implications for Employers and Newly Graduates}

\author{
Haidar Fadhil AL Qrimli* \\ Studies Planning and Follow Up Department, Iraq
}

Opinion

Today we live in a fast paced and ever changing world. Advances and ingenuity in engineering science, are at the root of most developments in various fields throughout history and this continues to be accurate nowadays. Engineering and technology has totally transformed the world in which we live, particularly within the last 150 years. However, it is also true to say that within each decade engineers have faced challenges and demands related to the age. In this article we discuss the emerging issues in engineering science today, with a specific focus on the field of mechanical engineering. We will also examine how these emerging issues may impact upon the engineering graduates of the future and the employment market.

Firstly, it is important to clearly define what we mean by 'Engineering'. We consider engineering as a branch of science, technology and mathematical understanding which is concerned with the understanding, design, building, and use of materials, machines, structures and systems. The goal of engineering is to improve the quality of life for society-it is concerned with solving problems. If we more specific about the field of mechanical engineering then we could define it as any engineering which is related to machines and mechanisms, so for example forces, materials, fluid dynamics and thermodynamics, heat transfer, etc. Therefore, mechanical engineering can cover a very wide skills base.

Many people in the West view the Industrial Revolution of the late 1700's and the subsequent mechanisation and industrial development throughout the $18^{\text {th }}$ and $19^{\text {th }}$ Century as the golden era of engineering. What was significant for engineering at this time in history was the apparently endless supply of natural resources such as coal, oil and gas, as well as a limitless water supply and abundance of materials. We now know today that this is not the reality and the world is facing an environmental and poverty crisis-humans are now having to face the consequences of past engineering glory days.

Furthermore, it is evident that the developments in engineering which have occurred in recent decades are not evenly distributed across the world. Advances in technology, communication, healthcare, transport and housing for instance, in general, are limited to certain parts of the world, leaving other parts with recurrent difficulties in basic areas such as sanitation, access to healthcare, suitable housing, etc. What is clear is that engineering has a massive role to play in development and this will become increasingly true in the near future.

It is widely accepted that the world is already overcrowded, and yet a recent report by the UN states that the world population is expected to grow from the current 7 billion to 9 billion by 2050 [1]. This large and growing population will all need access to food, clean water, effective sanitation, energy, education, healthcare and affordable transportation. It will be the responsibility of engineers to find the solutions for these issues through high levels of ingenuity and innovation, and thereby raise the living standards of the population. This is quite a challenge for the engineers of the future.

We can see now from this discussion two clear areas for advancement in the future beginning to take shape. The rise in population that we mentioned is creating some huge 
global issues which will affect humans everywhere in the world. The first of these emerging issues is focused around the reduction of poverty and the development of infrastructure to provide adequate access to food, water, shelter, etc. for all people around the globe. Secondly, but of equal importance, is the issue of climate change, which is now accepted as a reality, and we are already feeling the effects of it as a result of human activity. Our current use of fossil fuels is not realistic when we look at the timescales involved in the quantities of these non-renewable fuels and our levels of consumption. The only options for the future are to change our habits and behaviour, change the technologies that we are using and to find alternative fuels/energies. The two issues are in fact intricately linked as those most affected by many of the effects of climate change, such as food, shortages, flooding, drought, etc. will be those vulnerable people living in poverty. This may be seen to be ironic since they are also the least likely to be contributing toward climate change. Mechanical engineers will be challenged to develop new technologies and techniques that will support economic growth and development as well as embracing sustainability in every element to combat the effects of and avoid contributing toward climate change. Sustainability will be an increasingly important factor for the engineers of the future.

As we have already mentioned earlier, Mechanical Engineering is a very diverse branch of engineering which covers a wide array of skills. Mechanical Engineering graduates face a difficult decision when choosing which direction their career should take since mechanical engineering underpins development in areas of automotive, robotics, energy conversion/ generation, product design and manufacture. In light of the discussion above it is imperative that Mechanical engineers of the future also take greater initiative and responsibility in developing fields including water distribution, sanitation, green production and recycling, renewable and efficient energies. We mentioned that climate change is going to be a huge issue in the future and so engineering in the field of energy and finding new alternative energies will become increasingly important to help solve this problem. A recent UNESCO Report states that up to two billion people currently lack access to a basic power supply and an equivalent number lack access to safe water [2]. Engineers will need to find new ways to power our technologies, new ways to provide electricity, reduce emissions, etc. Finding new ways to manage the growing population and ease the effects of poverty also means that engineering in the fields of Water and Agri-Technology will need to become increasingly innovative in order to help solve problems related to providing clean water in a variety of environments across the globe and also solving food shortage crises.

The techniques and methods that engineers will be using in the future will need to change and develop, with a greater focus on smaller scale technologies and smaller timescales. Product design and manufacture is a field closely related to Mechanical Engineering and this too will need to consider sustainability in every aspect of this process, which as we already mentioned is going to need to be a key factor at the forefront of all Engineering. Sustainable development can be viewed as development which meets the needs of the present without compromising the ability of future generations to meet their own needs [3]. When carrying out any design and production Mechanical Engineers will need to think about the environmental lifecycle of a product and begin to take it from a cradle to grave model towards a cradle to cradle approach. Engineers will need to plan for the impact of the manufacture process and materials used on the environment, as well as making plans for the recycling, reuse or remanufacture of the product to eliminate waste. In turn, this will mean that methods such as 'concurrent engineering' will become more prominent as we will need to consider all aspects of a products design and manufacture from the outset to reduce timescales and be able to compete in the future.

Other fields related to Mechanical Engineering which will require innovation to solve the emerging issues in the near future include Automotive and Aerospace engineering. This is likely to increase in importance as we try to solve issues to do with gas emissions and improving the safety of vehicles. As the population grows there will be an ever-increasing amount of vehicles on the road and in the air - travel will need to become more efficient and cost effective to meet the demands of society. CAD modelling and an increasing demand on the use of software's has huge advantages for cost reduction, improving accuracy and reducing timescales. CAD software's will become more advanced in the future and this, combined with greater network capabilities will mean that engineers will be able to design whole systems using this software rather than as individual pieces. Another area in which we can already see growth is Nanotechnology since demand means that technologies are becoming smaller and smaller, for example you can now find Nano-technology being used in airbags in cars. In the future Nanotechnology will become incorporated into a wide variety of engineering projects and technologies. In order for Mechanical Engineers to keep up with the trends of tomorrow and ensure that their designs are innovative they will need to branch into areas like this which may not traditionally fall into their field. There will need to be a willingness for Engineers to broaden their knowledge and experience to bridge a variety of fields in order to remain competitive.

This leads us to contemplate what all this will mean for the Mechanical Engineers of the future who will graduate amid the complexity of these issues, and also how this may affect the employment opportunities for them. The impending growth of the population will have a huge impact in developing countries, as we have discussed. Therefore in the future it is likely we will see a greater number of mechanical engineers working overseas, particularly within these developing countries to find solutions to food and water shortages, sanitation issues and sustainable housing at low cost. Engineers will need to know how to develop locally appropriate engineering solutions as this will be the key to developing sustainably. For example when engineering solutions to water access issues in order for a concept to be successful the design must be entirely sustainable - with all of the materials coming from the local environment of the site where it will be used to enable it to be easily be repaired by non-specialists using local resources. The 
entry of more engineers into the global workforce will make the vocation much more global and competitive. Engineering service enterprises of all types will be competing globally for both projects and employees and so they will demand engineers with more than just technical skills. The future Mechanical Engineers will need to be resourceful, creative, adept at problem solving, and able to take a multidisciplinary, systems level understanding of problems. Future engineers will need to be life-long learners skilled at turning information into knowledge and mastering new skills.

The growing issue of climate change and the need to find alternative sources on energy will also see the demand increasing for Mechanical Engineers to move abroad for their work and necessitate working as part of global teams where there is a requirement to communicate with other engineers and professionals around the world. Therefore, in the future the ability to speak multiple languages will be a great asset and all engineers will need to have excellent communication and inter-personal skills. A high level of knowledge and skill in using technology for communication including social networking, Skype, etc. will become mandatory in order to be able to function in the workplace. Not only will future engineers need to do well in their degree and be competent in the related skills sets such as design and drawing skills or CAD, it will increasingly be key for them to develop social skills such as communication and leadership skills under pressure as they will need to address increasingly complex customer and investor requirements.

In the present climate, competition in the workplace and within engineering disciplines is high and this will continue to grow in the future. In order for Mechanical Engineering graduates to be able to compete they will need to have a wider knowledge base and field of experience to enable work across several disciplines. They will also need to have knowledge and skills of related topics within other fields of engineering such as biomedical, nanotechnology or electrical engineering. Employers will begin to demand mechanical engineers' expert in integrating different disciplines.

In conclusion, the world is continually changing and developing with a rapid growth in technology and competitiveness which will see the expectations and issues faced by Mechanical Engineers becoming increasingly complex. Critical problems such as battling climate change and focusing on development to improve conditions for an expanding population, many of whom are residing in poverty stricken or war ravaged circumstances, will come to the fore. Engineering has a colossal capacity to support and benefit society, of which Mechanical Engineers can play a massive part. The engineers of tomorrow will need to show a genuine concern for the issues of the global society and demonstrate a level of social responsibility to ensure that they themselves and their innovations, do not have a negative impact i.e. by damaging the natural ecosystems of the world. The employment market will offer a wider range of opportunities for Mechanical engineers, across the globe and across disciplines, however competition for jobs and between companies will increase and the specifications required from Mechanical Engineers will become greater and so Engineering graduates will need and ever increasing range of skills to ensure their success.

\section{References}

1. United Nations, World Population Prospects, 2015 Revision.

2. UNESCO, Engineering: Issues, Challenges and Opportunities for Development. Paris, France.

3. The United Nations' World Commission on Environment and Development. 